\title{
O narcisismo na docência universitária
}

\section{The Narcissism in University teaching}

EI narcisismo en la enseñanza universitária

\author{
Rafaela Brandão Alves* \\ Universidade Federal de Goiás - UFG, Goiânia, Goiás, Brasil \\ Bárbara Taveira Fleury Curado** \\ Universidade Federal de Goiás - UFG, Goiânia, Goiás, Brasil
}

\begin{abstract}
RESUMO
O presente artigo é um ensaio teórico que propõe discutir um dos não-ditos que circulam os corredores da academia: o narcisismo que perpassa a docência universitária. Para isso, será abordado o conceito de narcisismo para a Psicanálise, extraindo deste tanto a sua face estruturante, quanto aquela que aponta para o excesso na busca por olhares. Parte-se do ponto de vista de que a conjuntura socioeconômica vigente corrobora para o fomento desse narcisismo em todas as esferas da vida humana, o que não se faria diferente no fazer docente, já que o reconhecimento do professor é proporcional às suas linhas no currículo Lattes. Desse modo, este ensaio busca problematizar os efeitos do narcisismo na relação docente-discente e na produção do mal-estar sofrido pelos professores universitários. Por fim, é abordada a face oculta do ódio, subjacente à face do amor, como uma possibilidade de realizar o corte na relação espelhada entre docentediscente, a partir do que se daria a transmissão não apenas de saberes, mas da castração insistentemente disfarçada. O que a Psicanálise aponta como essencial quando se fala em transmissão do conhecimento.
\end{abstract}

Palavras-chave: narcisismo, docência, universidade, ideal, castração.

\section{ABSTRACT}

The purpose of the current article is to discuss in a theoretical essay, one of the unspoken circulating the halls of academy: the narcissism that runs through university teaching. For this, the concept of narcissism in psychoanalysis will be worked drawing both, the structuring face as the other one, that points to the excess in the search for looks. It starts from the point of view, which the current socio-economic situation corroborates to the promotion of narcissism in all areas of human life, which would not be different in the teachers' work, since professors' recognition will be proportional of their Lattes curriculum. Thus, this essay seeks to question the effects of narcissism in the teacher-student relationship and the production of discomfort suffered by university professors. Finally, the article addresses the hidden face of hatred, underlying the face of love, as being one possibility that would enable the section in the mirrored teacher-student relationship, from what would occur the transmission not only of knowledge 
but of insistently disguised castration. That's what psychoanalysis points as essential when talking about transmition of knowledge.

Keywords: narcissism, teaching, university, ideal, castration.

\section{RESUMEN}

El presente artículo se propone discutir lo que no se há dicho que circulan en los corredores da academia: el narcisismo em la que se trasluce la enseñanza universitária. A este fin se abordarán el concepto de narcisimo para el psicoanálisis aprovechando de este tanto de la cara estructurante cuanto aquella que apunta a lo exceso en la búsqueda de nuevas miradas. Desde el punto de vista de la coyuntura socioeconómica vigente corrobora para el fomento del narcisismo así como en hacer docente, ya que el reconocimiento del professor será proporcional em sus líneas en el Currículo Lattes. De este modo, se cuestionan los efectos de ese narcisismo de la relación estudiante-profesor y producción delmalestar que los profesores universitario han sufrido. Por último, se aborda la cara del ódio, subyacente a la cara del amor, como aquella que permitiria el recorte en relacion que se refleje en la relación estudiante-profesor, a partir do que transmisión ocorre no sólo de saberes, pero también de la castración insistentemente encubierta.

Palabras-Ilave: narcisismo, docência, universidad, ideal, castración.

\section{Introdução}

Amores à primeira vista são belamente vividos em ficções. São aqueles amores típicos em que a mocinha e o mocinho de pronto se apaixonam e, assim, compõem a imagem da completude: um não vive sem o outro. Haverá certamente conturbações nessa relação como mudanças do destino, terceiros que se põem entre a díade, brigas de famílias ou sabe-se lá que agente externo provocará a separação dos amantes para que ao fim se reencontrem e estejam livres para viver o amor indissolúvel. A Psicanálise mostra que essas ficções são disfarces à condição irrevogável do sujeito como ser furado, castrado e, por isso, incompleto. Diferentemente do que muitas vezes é narrado em fiç̧ões, as intempéries não são impostas apenas pelas contingências externas, como se bem quereria acreditar, mas também do encontro-desencontrado que é próprio da relação a dois.

Ficção, criação, fantasia. No caminho desse deslizamento significante apresentam-se construções imaginárias cujo sentido proposto pela Psicanálise vem ampliar a noção de algo meramente ilusório e falseado. A radicalidade da noção de imaginário para a teoria psicanalítica e para a compreensão do sujeito estaria na condição estruturante que o mesmo desempenha na formação do Eu. Considerar o imaginário e sua face estruturante impele pensar no conceito de narcisismo a partir de Freud e nas contribuições lacanianas para sua ampliação. Logo, o que as ficções nas telas fazem é reproduzir algo inerente ao sujeito, a saber, a dificuldade de 
abandonar as fantasias narcísicas de completude e de deixar cair as máscaras que o defendem do confronto com suas próprias fissuras.

O narcisismo, contudo, explica Freud (1914/1996), pode ser visto a partir de duas faces distintas. Uma que é estruturante e outra que pode ser alienante, sinalizando para as problemáticas desse mesmo narcisismo. Fenômeno que já despertou o interesse de diversas pesquisas, como nos textos de DeBord (1997) e Lash (1983), "A Sociedade do Espetáculo" e "A Cultura do Narcisismo", respectivamente. São referências clássicas para esse tema, pois abordam as transformações subjetivas frente às mudanças socioculturais decorrentes do modelo econômico vigente. Assim, o fenômeno do narcisismo enquanto problemática pode ser observado em diversas instâncias, a depender do objeto pesquisado.

Tendo essas questões em pauta, o presente texto propõe refletir sobre os efeitos do narcisismo no docente universitário e, concomitantemente, os efeitos na relação docente-discente. Considera-se de saída que algo da profissão de ser professor - mas não qualquer professor, é importante destacar que esse ensaio é uma pesquisa bibliográfica que não abrange a docência de forma ampla, se restringindo aos professores universitários - aponta para traços que alimentam o narcisismo, como a exposição aos olhares admirados.

A suspeita dessa ocorrência parte das condições objetivas que o fazer docente tem enfrentado, mais intensa e evidentemente nesse setor, qual seja a mercantilização da Universidade. Quanto maior a produtividade, maior o reconhecimento, mais convites, mais palestras, mais aberturas de eventos, mais olhares, mais artigos, mais papers, mais e mais e mais... 0 que poderia resultar desse ciclo senão a exaustão e o mal-estar recorrentemente queixados pelos professores? Anselmo (2011) defende na sua tese de doutorado, "Psicanálise e Educação: o mal-estar do professor universitário na atualidade", que os professores vivem a angustia diante da relação acelerada com o tempo: "Uma característica que acaba sendo naturalizada no contexto dos professores universitários, tal como se vê acontecendo com trabalhadores de grandes empresas que visam o lucro" (Anselmo, 2011, p. 44).

Consequentemente, diante das excessivas cobranças sentidas pelos docentes no ambiente acadêmico, eles cada vez mais se distanciam do ideal de professor construído pela sociedade e, claro, por eles mesmos; criando satisfações narcísicas, se submetendo aos ditames da produtividade. Para além dos sofrimentos físico-psíquicos decorrentes nos docentes, quais seriam os demais efeitos dessa satisfação narcísica na relação com os discentes? Esta é uma das questões que motivaram a escrita deste texto e que norteará a construção das ideias que se seguem. 
Será inicialmente discutida a submissão da Universidade às condições mercadológicas com fins de elucidar o pano de fundo que suscita o atual modus operandi dos professores e sua relação com o narcisismo enquanto conceito que demarca a estrutura do sujeito, e também como um sintoma que denuncia os excessos da busca por reconhecimento. Posteriormente serão trazidos, também a partir da Psicanálise, aspectos intrínsecos à relação professor/aluno e como eles apontam não somente para o amor então almejado pelos professores, mas para sua outra face, o ódio, inerente às relações e tantas vezes negado. Por fim, objetivou-se tensionar como a busca por admiração, amor e reconhecimento por parte de alguns docentes pode influir em uma (não) transmissão do saber a que se propõe transmitir.

\section{Condições que favorecem}

Cada época carrega consigo discursos característicos das condições concretas determinantes da sua particularidade histórica e sociocultural. Assim, ante a supremacia do capitalismo de que para tudo há preço no mercado, a educação se torna mais uma das instituições que se submete a esse regime. Esta - a educação - se tornou moeda de troca, não apenas nos superfaturamentos das licitações, mas, também, como meio de intervenção ideológica. Marx (1867/2013) mostra que não é interessante para a manutenção das diferenças de classes sociais que o conhecimento se estenda para fora da fronteira que demarca o que é da elite e o que é do resto. Conhecimento este que há algumas décadas mostrou sofrer transformações no sentido de se adequar ao que é demandado pelo mercado.

O discurso dominante, portanto, é de produtividade, individualidade e competitividade. A educação bem como a Universidade, uma de suas representantes, não escapa a essa lógica, "a universidade é uma instituição social e como tal exprime de maneira determinada a estrutura e o modo de funcionamento da sociedade como um todo." (Chauí, 2003, p.5). O fator decisivo na avaliação é a quantidade, na qualificação do professor através da produção de artigos, horas/aula, pesquisa e extensão; na nota da própria universidade que segue a mesma somatória bem como na avaliação dos discentes que também deslizam na mesma esteira de produção.

Marilena Chauí (2003) faz o diagnóstico das universidades no texto "A Universidade Pública sob novas perspectivas", no qual apresenta uma modificação no modo de funcionar das universidades que passaram a ser organização e não instituição social. De acordo com a autora, tais mudanças significam que sob a insígnia de ser uma organização, a universidade passa a ter a função instrumental de 
atender a objetivos particulares de eficácia e sucesso através de uma administração regida por planejamento, controle e êxito, sendo, pois, uma mera prestadora de serviços.

Nas palavras de Chauí (2003) a diferença entre a universidade enquanto uma instituição e uma organização social é que enquanto a primeira aspira à universalidade, a segunda aspira justamente 0 contrário, à particularidade, já que é isso que define sua eficácia no mercado. Assim, Chauí (2003) nos explica que a instituição busca responder as contradições impostas pela divisão social e política, enquanto a organização aceita estar em um dos polos dessa divisão social já que seu alvo não é vencer essa contradição, e sim competir com seus iguais.

É assim que como uma universidade operacional ela passa a ser controlada por contratos de gestão, avaliada por índices de produtividade e volúvel às instabilidades do mercado. A docência é entendida como a transmissão superficial de conteúdos e adestramento, os professores em sua maioria são contratados ou por excelência em algum objeto específico ou ainda por aceitarem se submeter a contratos temporários e precários (Chauí, 2003). Como consequência deste cenário, o conhecimento perdeu lugar para a informação, "(...) a informação prevalece sobre o próprio conhecimento, uma vez que o capital financeiro opera com riquezas puramente virtuais, cuja existência se reduz à própria informação." (Chauí, 2003, p. 8). A autora ressalta também os efeitos da lógica mercadológica na compressão espaço-temporal que podem ser entrevistos na diminuição do tempo para o estudo, no insuficiente tempo para a formação tanto de graduação quanto de pós-graduação e nos conteúdos que são passados apressadamente tendo como fonte artigos no lugar de livros clássicos.

Marcelo Pereira, psicanalista e professor, se debruçou nas investigações dos efeitos desse quadro social no psiquismo dos docentes, sobre o qual tece relevantes considerações no texto Qual é o nome atual do mal-estar docente? Para o pesquisador, as precárias condições de trabalho (estruturais), as exigências produtivas e o isolamento dos discentes corroborariam para a fabricação da conjuntura de esgotamento, absenteísmo e hipermedicalização. Os professores: "(...) queixam-se de uma certa paralisia profissional e de padecerem de depressão e fenômenos associados como estresse, esgotamento, transtorno bipolar, alimentar, de pânico e consumo de álcool (Pereira, 2014, p. 1-2).

Tamanho sofrimento parece ser consequência da submissão à lógica da produtividade, já que não há como negar a grande influência das contingências sociais. Todavia, tais sintomas para perdurarem estão ligados a ganhos secundários (Freud, 1926/1996c), certamente alguma satisfação, ainda que inconsciente, é dali retirada. Afinal, ser professor carrega algum tipo de poder, já que são eles um dos 
principais agentes transmissores do conhecimento. Mas sob o que se constrói essa imagem de poder vinculada aos docentes? Anselmo (2011) afirma que ela se apoia sob o ideal de como deve se portar e se mostrar um professor digno do lugar de mestre, assim, "(...) existe uma imagem ideal do ser professor que corresponde àquele que é capaz de ensinar sem perdas, por um lado, e um homem real, de outro, que não consegue atender às exigências de perfeição." (Anselmo, 2011, p. 54).

Para compreender melhor esse ideal criado acerca das responsabilidades e habilidades do professor, será trazido agora o conceito de narcisismo, que se faz aqui fundamental para entender os ganhos que sustentam o docente nesse ideal de mestre.

\section{Narcisicamente falando}

O conceito de Narcisismo é desenvolvido mais diretamente no texto "À guisa de introdução ao narcisismo", no qual Freud (1914/2004) irá por meio dos exemplos do enamoramento, da hipocondria, da dor e da psicose, entrever que o Eu é ele mesmo fonte dos primeiros investimentos da pulsão, ao que dará o nome de narcisismo primário. A libido que Freud (1914/2004) relata, primeiramente, tomar o eu como objeto é estruturante e fundamental para o surgimento da instância do Eu. O tempo inaugural, anterior à estruturação do Eu, é marco de um corpo despedaçado, sem borda, sem distinção do dentro e do fora, do que é prazer/desprazer. A este conjunto de qualidades Freud (1914/2004) dá o nome de narcisismo primário, situando o secundário quando já há ligação da pulsão a objetos externos havendo, pois, a separação do que é interno e externo e do que é fonte de satisfação ou não. Todavia, fica um tanto obscuro nessa apresentação freudiana como se dá essa passagem e, mais, como desse eu fragmentado irá emergir o Eu estrutura. É a partir dessa proposição freudiana que Lacan (1953-1954/1991) irá enunciar o registro do imaginário alicerçado na sua teoria sobre o estágio do espelho.

Freud (1914/2004) relata que todo ser humano reluta em abandonar o narcisismo, criando para si uma idealização do que ele já fora (em tempos de narcisismo primário), ou seja, a fantasia de que em um momento primordial se era completo e satisfeito. Essa idealização é a projeção de um Eu que cada um cria e luta para retomar, explica Freud. Observa-se que a palavra ideal ganha destaque e Lacan (1953-1954/1991) fez questão de realça-la. Ideal tem dentre seus sinônimos, fictício, irreal, perfeito e modelo, termos que ressoam com as palavras - perfeição e completude - usadas por Freud (1914/2004. França (1997) afirma que ambas são da ordem da ficção, de uma 
mentira construída para tamponar a verdade da incompletude, portanto, do registro do imaginário.

A teoria lacaniana mostra que esse registro - imaginário - visa tamponar a falta fixando um único sentido, onde qualquer vacilação arrisca o desvendar do que jaz por traz, o sem sentido do ser. 0 imaginário tem como protótipo o espelho, e "[...] a característica do espelho é não refletir o que falta. Ou, ainda, não há imagem daquilo que falta. Portanto, se a falta não tem imagem, o imaginário é, por princípio, um registro sem faltas, correspondente à onipotência do eu" (França, 1997, p. 80).

O ideal está nos dois polos do narcisismo, narcisismo primário e secundário, o que se explicita com as noções de eu-ideal e ideal de eu presentes em Freud (1914/2004), mas sem uma distinção clara, que será posteriormente delineada por Lacan. No texto lacaniano "Seminário livro 1: Os escritos técnicos de Freud" (1953-1954/1975) ele pontualmente desdobra essa denominação freudiana diferenciando os dois ao incluir o primeiro no registro do imaginário e o segundo do simbólico.

Lacan (1953-1954/1991) esclarece que o eu-ideal se relaciona com a imagem corporal construída a partir dos traços advindos do outro, ou seja, essa imagem projetada sobre o sujeito é arquitetada em cima daquilo que cada um acredita ser desejo do outro, ideal estruturante, porém inalcançável, já que o que se imagina ser desejado é sempre um engano. Assim, "ao assumir sua imagem, o sujeito é marcado por um olhar, que desenha uma forma ideal e que se torna um sonho de domínio. Esta imortalidade sonhada e ligada a uma forma, o eu ideal, tenta sustentar uma unidade que não há" (França, 1997, p. 132).

Lacan (1953-1954/1975) afirma que a formação dessa imagem unificada, através do estágio do espelho, se dará na identificação com a imagem do outro que é tomado para si, processo este legitimado pelo olhar reconhecedor do outro. Sobre a função de destaque do ideal nos dois narcisismos, França (1997) acrescenta que o eu sempre carrega seu ideal, ou seja, essa imagem daquilo que ele acredita ter sido um dia (completo no narcisismo primário) e daquilo que aspira ser, ou melhor, voltar a ser. Enquanto um polo (ideal de eu) olha para o passado de maneira saudosista, o outro (eu-ideal) almeja alcançar essa idealização no futuro.

Se nesse polo narcísico a pergunta preponderante poderia ser enunciada como, o que o outro quer de mim, no segundo polo poderse-ia formulá-la como, o que eu acho que o outro quer de mim. A diferença? A separação do eu e do outro, pois é preciso primeiramente que seja demarcada da fronteira entre o que é interno e o que é externo, para que então outro seja tomado em sua alteridade Mas, para que isso ocorra é necessário o reconhecimento da falta do outro, pois reconhecê-la implica no reconhecimento da própria falta, é o que França (1997) nomeia como lapso de imagem. 
Aqui se dá o ponto de desalinenação ao desejo do outro e ao que este espera do sujeito, "A função do eu, efeito de imagem, é a da alienação, lugar do engano que se sustenta sobre a incompletude da falta. O lapso de imagem faz irromper o des-engano da des-ilusão narcísica" (p. 85).

Assim, o júbilo é evanescente. No mesmo instante em que o olhar é reconhecimento e investimento sobre a forma unificada do eu, é também olhar vacilante, pois no olhar resta o brilho daquilo que falta. O olhar não se fixa, é móvel, olhar para o nada ou para o tudo, mas não para um só. O sujeito depara-se, pois, com a verdade inexpugnável de que se falta para o Outro, falta também para si, a máscara da completude cai e o ideal fica ainda mais distante.

Como já dito, o amor infantil de que gozava o infante é atualizado no eu-ideal e continuado no Ideal do eu, ideais construídos a partir da relação com o outro cuja satisfação resultaria da realização desses ideais (Lacan, 1953-1954/1975). Tais ideais se formam nos primeiros tempos de estruturação do sujeito, mas são reelaborados a partir das modificações nas exigências externas, ou seja, a satisfação é balizada pelo momento histórico-social de inserção do sujeito.

Assim, o ideal de professor pode se modificar de acordo com as demandas de cada época vivida. Atualmente, o docente é avaliado tanto pelas instâncias externas (Capes, MEC, Universidade) como pela instância interna herdeira desses ideais, o Supereu. Pereira (2014) discorre sobre a relação entre os imperativos superegóicos e o mal-estar vivido pelos docentes ao dizer que quando o professor avalia o aluno, ele está avaliando seu próprio trabalho, ou seja, há uma responsabilidade na transmissão do conhecimento que recai constantemente no professor.

Para o autor em questão, o sentimento de fracasso e impotência revelariam de saída a pretensão de onipotência que secretamente impulsiona o fazer docente. Todavia, Pereira (2014) aponta o outro polo da questão. Ou seja, não se trata apenas do narcisismo do docente, logo, de um querer ser sempre assertivo, mas também do risco de deposição deste, quando o mesmo não corresponde ao que Ihe é esperado. Assim, Pereira (2014) afirma ser a profissão de docente um lugar incerto ao qual muitos docentes não reconhecem de antemão seus componentes conflitantes e de possíveis desmascaramentos narcísicos.

O discurso da competência levaria, de acordo com Pereira (2014), à desautorização do mestre, pois os docentes ficariam desamparados diante de suas falhas e da incompetência em atingir os ideais esperados, "o professor do cotidiano, muito distante do Mestre idealizado de outrora, ao invés de interrogar esse discurso, vive com esta máscara e com o medo de que ela caia." (Boaventura, Paulino \& Pereira, 2008, p.9). Almeida e Domingues (2011) no artigo "Sociedade, Educação e Narcisismo: da relação do professor com o 
não-saber", resumem a tênue fronteira vivida pelo professor entre 0 suposto e deposto mestre. Os autores afirmam que o docente carrega consigo um ideal narcísico que o coloca "ora poderoso frente a alunos carentes de respostas e submissos aos seus desejos, ora sentindo-se solitário e impotente frente a situações em sala de aula para as quais não encontra respostas" (p. 9).

Almeida e Domingues (2011) evidenciam que o movimento pendular competência-incompetência e o pathos dele consequente se relaciona com o modo como o sujeito/docente se porta diante do não-saber. Há uma cobrança interna nesses professores advinda de um supereu rígido que carrega consigo esse ideal de eu ainda alienado no narcisismo primário. Ideal reforçado pela cultura e meio científico que também alimentam essa crença no mestre, ou seja, em uma pessoa que detém $O$ saber.

Lacan, no seminário $O$ avesso da Psicanálise, fala sobre o discurso da histérica como sendo este que está constantemente na busca do mestre, de alguém que detenha $O$ saber, esse $O$ representando aí todo saber possível, logo, aquele que saiba sobre seu inconsciente. Lacan (1969-1970/1992) ainda afirma que esse discurso é base para toda neurose, já que é uma forma de recalcar a castração do Outro. Ou seja, de uma forma ou de outra, essa busca por alguém que detenha respostas está presente em todos. Isso se torna nítido quando se trata de educação. O professor ainda é um dos lugares privilegiados de mestria na sociedade, lugar daquele que detém as respostas para as mazelas alheias. Diante dessa sobrecarga de responsabilidade, desse desejo de que alguém detenha todo saber, seria sintoma do professor tudo querer saber? Ou ainda, qual o lugar da ignorância no ensino-aprendizagem? Pois como apontado, é nítida a angústia proveniente dos docentes quando colocados diante de sua ignorância.

\section{Imposturas do não-saber}

É notável que a sala de aula seja um dos palcos de atuação dos docentes. Ali muitos deles gozam sob os olhares devotos dos discentes, expressando a excitação com o saber acumulado, com a possibilidade de despejar suas pesquisas e certezas. No momento em que falam é como se nada mais existisse além do afetamento pelo saber, e diante desse impacto ele espera que o mesmo efeito ocorra nos ouvintes. Querem olhares atentos, perguntas e adoração. 0 desconcerto perante questões que extrapolam o saber possuído é visível em muitos casos, ainda quando tentam solapá-lo com respostas rasas e até mesmo incorretas.

Outro ambiente que favorece cenas teatrais são as bancas de defesa de mestrado e doutorado. Muitas vezes aqueles que deveriam ser os 
protagonistas, o discente e sua produção, se tornam coadjuvantes perante o duelo que se firma entre os convidados da banca. Quem sabe mais? Doutores do conhecimento disputam narcisicamente quem brilhará naquela bancada, logo o que era para ter caráter de contribuições se torna conferências, palestras, enfim, espetáculos de saberes. Mas o que tanto saber visa obstruir?

Green descreve em "O Desligamento" que o desejo pela leitura é um desejo pelo conhecimento, por algo a mais que ainda não se tem acesso, uma curiosidade que se manifesta desde o encantamento pela capa do livro até a leitura de cada página. O autor afirma que todo desejo de saber é um desejo de saber sobre a sexualidade.

Ler e escrever, narra Green (1994), são pulsões parciais domesticadas pela educação, ou seja, pulsões inibidas quanto ao seu objetivo, dessexualizadas e deslocadas, por isso mesmo, sublimadas. Freud (1930/1996d) já havia dito isso em "Mal-estar na civilização", mas Green (1994) retoma para falar do desejo de escrever e ler como um substituto afastado de um desejo de ver e saber que está de acordo com toda curiosidade sexual. Para o autor, tal curiosidade foi sublimada, perdendo assim seu caráter sexual e transposta a outro objeto, no caso os livros, e nos dias de hoje, podemos dizer que a ciência, mais que os livros, ocupam esse lugar de mestria, representado preferencialmente pela figura da academia.

Freud (1930/1996d) já havia dito que o desejo de ver e saber se mantém após a sublimação promovida pela cultura, mas não mais com o caráter sexual. Após essa operação ele se direciona para um fim social. A ciência, a academia e a figura do professor seriam então figuras imaginárias construídas socialmente para representar os detentores do saber. Uma promessa de conhecimento, de um saber ligado à nossa sexualidade, à nossa existência como tal. A literatura PSI pode ser compreendida aqui como um saber sobre essa parte inconsciente que rege as escolhas e vidas de todos. Mais do que os livros, a academia representa bem esse lugar de mestre, e 0 professor, de sujeito do suposto saber.

Todavia, como o próprio Freud (1930/1996) disse com a descoberta do inconsciente, nem tudo pode ser sublimado como nem tudo pode ser sabido. A sublimação é uma das formas de criar a partir desse não-saber que insiste em se apresentar. O sujeito produz arte, ciência, filosofia, religião, mas ainda assim, por ser sujeito do inconsciente, resta sempre algo que não será sabido, que insistirá em não se escrever (Lacan, 1964/2008). Reconhecer o limite no saber, esse impasse radical, é reconhecer a própria castração, movimento que implica o face a face com a angústia e que por isso é diariamente evitado pelo sujeito. Maurano (2006) discorre sobre a relação do sujeito divido e o saber sublinhando a tentativa daquele em dar sentido à vida. 
O saber, como mostra Maurano (2006), possui um lugar necessário na vida do sujeito como sustentação em face da ausência de significados que continuamente o atormenta. Ausência de significado sobre si, sobre o mundo e o devir. A busca pelo saber pode vir como uma forma de dar significados múltiplos e singulares ao existir de cada um. Contudo, tomar o saber como absoluto incorre nos excessos que foram apresentados como na negação do não-saber tantas vezes visto na docência universitária. Para Almeida e Domingues (2011) o saber colocado sob essa forma de controle levaria ao que eles chamam de gozo do saber-poder, um saber tomado como verdade que na tentativa de suturar o vazio implicaria no esvaziamento do sujeito, "vive-se então um processo de eterno recobrimento do não-saber existencial, refletido no encobrimento de não-saberes diversos." (Almeida \& Domingues, 2011, p. 2).

Se para a Psicanálise o sujeito é cindido em sua origem, um des-ser, a tentativa de ocultar essa divisão, esse inconsciente que insiste em mostrar a ausência do dado pronto, implicaria senão no apagamento do próprio sujeito. Lacan no texto "Alocução sobre o ensino", de 1970, traz relevantes contribuições sobre o que seria o ensino, não especificamente da Psicanálise, mas sobre o "ensino puro e simples" (Lacan, 1970/2003, p. 302). Segundo o psicanalista, para que algo seja tomado como ensino não significa que com ele se tenha aprendido algo, que dele resulte um saber. Ou seja, algo na relação entre aquele que ensina e aquele que aprende extrapola o âmbito do saber.

Para Lacan (1970/2003), seria o que é da ordem do efeito, efeito de divisão, de cisão que acomete o professor em sua essência e, ao mesmo tempo, aquele que o escuta, que tem notícias dessa queda de imagem. Ou seja, o professor para assumir seu lugar face ao saber possível de ser transmitido deve reconhecer a si próprio como sujeito divido, sabendo, pois que "a verdade pode não convencer, o saber passa em ato." (p. 310).

Isto é, o que se passa em ato no ensino é justamente aquilo que não pode ser ensinado conscientemente, que não está sob domínio de conceitos, mas aquilo que indica o corte e não o gozo no saber. Sobre essa posição não narcísica proposta por Lacan, Maurano (2006) acrescenta que lecionar, é um comprometimento com a

Parcialidade da verdade, com sua estrutura de ficção, implica a transmissão de um saber que não se sabe, ou seja, a transmissão de um enigma, um dizer pela metade, que é fisgado pela verdade, mas que não elide o abismo que há entre esta e o saber. (p. 222)

Desse modo, manter o abismo entre a verdade e o saber possibilita preservar a transmissão do que transborda o conteúdo, deixando 
efeitos de castração no outro. O abismo, portanto, também se faz na relação entre os sujeitos, de modo que a relação docente/discente não poderia escapar a esta condição. A ilusão de uma relação de concordância, de complementaridade e pura admiração deve dar lugar àquilo que muitas vezes é rechaçado e evitado, o ódio. Essa face admitida nas entrelinhas ocupa o lugar dos não-ditos que ecoam pelos corredores nas universidades é desmascarando o tabu entorno do narcisismo na docência universitária.

\section{Da ambivalência à transmissão do furo no saber}

Freud no texto "Totem e Tabu" (1913 [1912]/ 1996a) demarca o conceito de tabu falando sobre os não-ditos que fazem efeito pela sua ausência, paradoxo este que anuncia a presença daquilo que falta. Para o autor, os rumores vez ou outra ganham voz ativa e denunciam o que estava sendo negado. O tabu, ou seja, esse não dito que produz efeitos, denotaria uma coisa, um lugar, uma pessoa ou uma condição transitória, que possuiria um atributo misterioso (Freud, 1913 [1912]/ 1996a).

Segundo Freud (1913 [1912]/ 1996a), esse tom mágico do atributo seria consequência do sentido contraditório que ele carrega, como algo ao mesmo tempo sagrado e impuro.

Freud (1913 [1912]/ 1996a) afirma que ao analisar profundamente a veneração e idolatria voltadas às figuras de mestria, referidas a essas pessoas/coisas privilegiadas, vê-se que existe uma corrente oposta no inconsciente - de hostilidade intensa. Para o autor, o tabu é exercido aí e carrega consigo um sentido duplo: a ambivalência emocional.

Feitas essas considerações sobre o caráter ambivalente das proibições, tem-se que o tabu em torno do narcisismo na docência possui a função de afastar o sentido oposto daquele aparente. Se os docentes são reverenciados no lugar de mestres, de amados e respeitados, a face ambivalente que estaria interditada é a do ódio, da repulsa, da hostilidade e da discórdia que não possui espaço para ser expressa. Operaria, assim, o corte na relação díade entre docente/discente ao ter lugar o ódio e não somente o amor e seu impulso à ligação.

Sustentar ser também odiado (e não somente amado/venerado) é dar espaço para ouvir - ter notícia de - sua castração, ou seja, seus limites, erros, incompetências e não-saber - características próprias de qualquer fazer humano. Tarefa difícil por motivos narcisicamente estruturais, como Freud (1914/2004) já havia apontado, mas que é potencializado quando a universidade entra na lógica da produtividade capitalista, como Chauí (2003) denuncia, exigindo do professor um ideal que lhe é impossível de ser alcançado. 
Dejours (2005) discorre sobre as consequências dessa exigência de reconhecimento, gozo e poder, próprias do narcisismo e potencializadas nos tempos da globalização, onde o mundo do trabalho privilegia a objetividade convocando as pessoas a uma guerra econômica de cunho individualista e competitivo. Para o autor a saúde física e mental está diretamente ligada à organização do trabalho, que se manifesta hoje através de uma ideologia neoliberal. Nesta, o homem é visto como livre e capaz de produzir sua fortuna por si mesmo - se aceitar se submeter às leis do mundo do trabalho. Ou seja, o fracasso e sucesso de cada um são vistos como dependentes apenas de sua própria competência, impedindo as pessoas de perceberem as dificuldades e o sofrimento como resultado de ações políticas, econômicas e sociais (Dejours, 2005).

Falando de outra forma, o neoliberalismo contribuiu para o desenvolvimento do individualismo, alimentando o narcisismo de todo sujeito que se insere nessa lógica. Assim, a busca pelo saber, como também pelo reconhecimento e poder se tornam não só individuais, como de cunho meritocrático. No mundo moderno, torna-se corriqueiro que a determinação das escolhas profissionais tenha como objetivo poder, gozo e reconhecimento.

Contra essa lógica adoecedora, Dejours (2016) enfatiza que a saúde mental no trabalho não depende apenas do talento individual de cada um, sendo o meio mais poderoso de alcançá-la: a ajuda mútua, a solidariedade, o viver juntos, ou seja, a construção coletiva do saber. Essa ideia vai de encontro ao aqui proposto, já que pela relação de mestria - logo, hierárquica - existente na universidade, a construção do conhecimento é vista mais de forma individual e objetivada através do currículo lattes de cada um.

A competitividade, tanto quanto o individualismo - formas narcísicas de expressão - se fazem presentes na universidade. O que para Dejours (2005) torna-se mais um empecilho para a produção de saber e da saúde mental do que um aliado. O que aqui está sendo proposto diz menos do quantum de saber que cada docente tem, e mais de um saber-fazer, construir e transmitir, de um manejo com o que se sabe e com o que não se sabe, que para Dejours (2005) é sempre mais construtivo coletivamente.

Retomando a discussão sobre a ambivalência amor-ódio na relação docente/discente, para sustentá-la traz-se aqui um texto pouco referenciado de Freud e que curiosamente foi escrito no mesmo ano daquele que desenvolve o conceito de narcisismo. Ambos escritos em 1914, o texto intitulado "Algumas reflexões sobre a psicologia escolar" é um belo ensaio sobre a relação professor/aluno em que o psicanalista traz suas próprias experiências e afetos trocados com seus mestres quando ocupou o lugar de aluno para dizer dos sentimentos ambivalentes que circulam essa relação. 
Freud (1914/1996b) diz que na função de psicanalista, ao investigar o que ocorre na relação aluno/professor, estaria mais interessado no que é da ordem do inconsciente que do consciente e mais interessado nos processos emocionais do que nos processos intelectuais. Assim, confessa que ao se encontrar com um antigo mestre se perguntou sobre o que mais exercia influencia dessa figura sobre ele, se um interesse pela ciência ou algo da personalidade desse mestre. E ressaltando a ambivalência presente nos afetos investidos nos professores responde à sua inquietação dizendo:

Nós os cortejávamos ou lhes virávamos as costas; imaginávamos neles simpatias e antipatias que provavelmente não existiam; estudávamos seus caráteres e sobre estes formávamos ou deformávamos os nossos. Eles provocavam nossa mais enérgica oposição e forçavam-nos a uma submissão completa; bisbilhotávamos suas pequenas fraquezas e orgulhávamo-nos de sua excelência, seu conhecimento e sua justiça. (...) Estávamos, desde o princípio, igualmente inclinados a amá-los e a odiá-los, a criticá-los e a respeitá-los. (p. 248)

O fragmento acima traduz com palavras e imagens a relação vivenciada como aluno na história de cada sujeito com seus mestres. E como o próprio Freud (1914/1996b) relata, essa posição de submissão e confronto, de admiração e desapontamento seriam reatualizações de sentimentos ambivalentes outrora sentidos face às figuras parentais. Posição própria do lugar de mestre, afirma Lacan no seminário $O$ avesso da Psicanálise.

Ou seja, os professores seriam figuras de autoridade investidas de representações que anteriormente estavam relacionadas às imagos paternas. Isto é, para compreender o que se passa nessa relação transferencial é preciso considerar os traços que apontam para as identificações das primeiras relações, pois "a menos que levemos em consideração nossos quartos de criança e nossos lares, nosso comportamento para com os professores seria não apenas incompreensível, mas também indesculpável." (Freud, 1914/1996b, p. 250).

Se a relação parental é constituída por amor e ódio é porque é marcada pelo movimento de queda do idealizado. O super-herói não consegue salvar a princesa de seus machucados, a santa mãe não é tão santa quanto se acreditava ser, assim, as imagens necessariamente construídas são em um tempo depois furadas, 0 professor não sabe tudo e o psicólogo também possui dores e lástimas diárias. Nesse sentido, o que ocorre na relação professor/aluno seria uma forma de elaboração desse primeiro tempo e devido a essa função no psiquismo deve ser interpretada com 
ressalvas e cuidado por aqueles que desempenham a função de autoridade. Mais uma vez será trazido um trecho do texto freudiano, nele Freud (1914/1996b) revela essa percepção dolorosa e necessária que todo filho passa ao visualizar a castração do pai:

De seu quarto de criança, o menino começa a vislumbrar o mundo exterior (...). Descobre que o pai não é mais o poderoso, sábio e rico dos seres; fica insatisfeito com ele, aprende a criticá-lo, a avaliar o seu lugar na sociedade; e então, em regra, faz com que ele pague pesadamente pelo desapontamento que lhe causou. Tudo o que há de admirável, e de indesejável na nova geração é determinado por esse desligamento do pai. (p. 249)

É preciso, pois, que o ideal caia, que a fiç̧ão seja confrontada com a realidade, que o imaginário seja furado pelo real. As fantasias não se sustentam indefinidamente, pois precisam estar em movimento de construção e desconstrução, somente assim o sujeito pode se haver com o que não sabe e nunca saberá, com o que está fora do seu domínio - o real da castração, furo de todo humano. O ódio deve fazer barulho face o silêncio uníssono do amor, deve operar cortes e quedas em identificações narcísicas. Se isso acontece nos lares, como não esperar a transferência-para o meio acadêmico, já que este é continuação de uma transmissão de saber que foi antes despertada junto aos pais?

O confronto e a discórdia deveriam ter lugar nas bajulações de salas de aula e as figuras majestosas deveriam ser questionadas por cada um e pelos outros. Desse modo, o império das aparências poderia ser atacado em suas bases e toda essa conjuntura de mal-estar presente na docência, bem como da excessiva produtividade cultivada pelo narcisismo, poderiam ser desveladas em suas causas e então contestadas. Abrindo assim um lugar para o não saber, que como a Psicanálise mostra, seria também uma abertura para o desejo que move a busca de saber. Como isso ocorre?

A Psicanálise vem mostrar que o não saber pode ser mais produtor de conhecimento do que uma resposta pronta, dada, fechada. O não saber é motivador, ele movimenta o sujeito na busca de algum saber. Fala-se aqui algum saber, não $O$ (todo) saber. Isso porque por ser sujeito de inconsciente, o saber nunca é completo e certeiro. Lacan (1964/2008) no "Seminário 11" aponta quanto a certeza pode ser enganosa, já que o saber é sempre barrado, incompleto e perdido para o sujeito freudiano. E é justamente por assim sê-lo que instiga-o a se movimentar, logo, lhe causa desejo. Lacan (1964/2008), retomando Freud, busca então defender que o furo no saber pode ser o combustível para uma função bela e criadora, pois é essa falta, 
essa ausência de respostas, que abre espaço para o movimento de busca do conhecimento.

Quando se olha a busca de muitos professores por respostas incessantes, por dar conta de responder ao ideal de mestre que a sociedade e eles - superegoicamente - se conferem, vê-se que tal jornada desgasta não só cada um como pessoa e profissional, como empobrece e compromete a busca pelo conhecimento, pela transmissão de saber e pelo desejo de conhecer dos alunos e das instituições que por eles são formadas.

Lacan (1969-1970/1992) sugere que o discurso analítico fure o discurso universitário. O que é pedido nessa afirmação é que se abra espaço para o não saber através do reconhecimento dele em cada um, no outro e na ciência. Uma queda do imaginário narcísico de que é possível alcançar A verdade absoluta sobre si e sobre o mundo, de que é possível tudo dar conta. Queda fálica, já que diálogos tendem a ser abertos e as divergências tendem a entrar em campo, tanto quanto a face do ódio que existe no amor. Para Lacan (1992) a transmissão do ensino é feita mais por um reconhecimento de sua própria ignorância do que por uma falação de saberes fechados que mais matam o desejo do discente de ali estar presente, do que o motivam a desejar, a construir um espaço de troca, pesquisa e produção do conhecimento.

Reconhecer a própria castração, é isso que Freud e Lacan propõem e que esse artigo defende como uma forma de resistência à lógica mercadológica que atinge as instituições de ensino, tanto quanto os docentes e discentes. Reconhecer o furo em si, no saber e no sistema imposto, possibilita que cada docente aceite - minimamente - o erro, a ausência de respostas, a fala do aluno, o diálogo, a discordância e a diferença.

Quando cada docente reconhece seu limite, suas errâncias e nãosaberes, abre-se espaço para a transmissão da castração. Ou seja, a busca deixa de ser a da negação desse furo - tamponamento narcísico através de uma imagem falaciosa - e passa-se a refletir sobre o que fazer com esse furo, logo, abre-se espaço para 0 potencial criador.

O professor que não sabe e por isso mesmo se mantém na construção do conhecimento - na universidade - abre a possibilidade de criar espaços para debates e reflexões mais sinceras e construtivas no âmbito acadêmico, logo, de um fazer inovador. Reconhecer a própria falta não é apenas um ato de respeito a si mesmo, é também a possibilidade apontada por Lacan (1964) de transmissão desta aos alunos. Pois quem não sabe, deseja e quem deseja, busca conhecer. 


\section{Referências}

Almeida, I. M. M. Z. P., \& Domingues, K. G. (2011, setembro). Sociedade, Educação e Narcisismo: da relação do professor com - não-saber. $V$ Colóquio Internacional Educação e Contemporaneidade, São-Cristovão, SE, Brasil. ISSN: 19823657.

Anselmo, A. C. (2011). Psicanálise e Educação: o mal-estar do professor universitário na atualidade. Tese de Doutorado. UFP, Curitiba.

Boaventura JR., M, Paulino, B. O., \& Pereira, M. R. (2008). O discurso da competência como fator de desautorização docente. In: Formação de profissionais e a criança-sujeito, 7. São Paulo. Proceedings online. Available from: <http://www.proceedings.scielo.br/scielo.php?script=sci_arttex t\&pid=MSC0000000032008000100055\&lng=en\&nrm=abn > . Acess on: 21 Mar. 2016.

Chauí, M. (2003). A universidade publica sob nova perspectiva. In: Revista Brasileira de Educação. No 24.

Debord, Guy (1997). A Sociedade do Espetáculo. Rio de Janeiro: Contraponto.

Dejours, C. (2005). O fator humano. Tradução de Maria Irene S. Betiol e Maria José Tonelli. Rio de Janeiro: Editora FGV.

Dejours, C. (2016). Organização do trabalho e saúde mental em Organização do trabalho e adoecimento - uma visão interdisciplinar: / Organizadores, Kátia Barbosa Macêdo [et al]. Goiânia: Ed. Da PUC Goiás.

França, M. I. (1997). Psicanálise, estética e ética do desejo. São Paulo: Perspectiva.

Freud. S. (1996a). Totem e tabu. In: Obras psicológicas completas: edição standard brasileira. Vol. XII. pp. 13- 163 Rio de Janeiro, RJ. (Obra originalmente publicada em 1913 [1912]).

Freud, S. (1996b). Algumas reflexões sobre a psicologia escolar. In: Obras psicológicas completas de Sigmund Freud: edição standard brasileira. Vol. XIII. pp. 244-250. Rio de Janeiro: Imago. (Texto originalmente publicado em 1914).

Freud, S. (1996c). Inibição, sintoma e angústia. In: Obras psicológicas completas de Sigmund Freud: edição standard brasileira. Vol. XX. pp. 81-171. Rio de Janeiro: Imago. (Texto originalmente publicado em 1926).

Freud, S. (1996d). Mal estar na civilização. In: Obras psicológicas completas de Sigmund Freud: edição standard brasileira. Vol. XXI. Rio de Janeiro: Imago. (Texto originalmente publicado em 1930 [1929]).

Freud, S. (2004). À guisa de introdução ao narcisismo. In: Hanns, L. A (Coord.). Escritos sobre a psicologia do inconsciente. In: 
Obras psicológicas de Sigmund Freud. v. 2. Rio de Janeiro: Imago. (Texto originalmente publicado em 1914).

Green, André. (1994). O desligamento: Psicanálise, antropologia e literatura. Rio de Janeiro: Imago Ed.

Lacan, J. (1975). Seminário livro 1: Os escritos técnicos de Freud. Rio de Janeiro, RJ: Zahar. (Obra originalmente publicada em 19531954).

Lacan, J. (1992). O seminário, Livro 17: O avesso da Psicanálise . Rio de Janeiro: Zahar. (Texto originalmente publicado em 19691970).

Lacan, J. (2003). Alocução sobre o ensino. In: Outros Escritos. Rio de Janeiro, RJ: Zahar. (Originalmente publicada em 1970)

Lacan, J. (2008). O Seminário, livro 11: os quatro conceitos fundamentais da Psicanálise (Texto originalmente publicado em 1964). 2. ed. Rio de Janeiro: Jorge Zahar.

Lasch, C. (1983). A cultura do narcisismo: a vida americana numa era de esperanças em declínio. Tradução de Ernani Pavaneli. Rio de Janeiro: Imago.

Marx, K. (2013). O capital. Livro 1: O processo de produção do capital. Vol. II. Tradução de Reginaldo Sant'Anna. São Paulo: Boitempo. (Originalmente publicada em 1867).

Maurano, D. (2006). Um estranho no ninho ou a Psicanálise na universidade. In: Lacan e a formação do psicanalista. Marco Antônio Coutinho Jorge (Org.). Rio de Janeiro: Contra capa.

Pereira, M. R. (2014). Qual é o nome atual do mal-estar docente? In: Presença Pedagógica (Dimensão), 20(117), mai/jun.

\section{Endereço para correspondência \\ Rafaela Brandão Alves}

Universidade Federal de Goiás - UFG

Av. Esperança, s/n, Campus Samambaia, CEP 74690-900, Goiânia - GO, Brasil

Endereço eletrônico: brandaoalvespsi@gmail.com

\section{Bárbara Taveira Fleury Curado}

Universidade Federal de Goiás - UFG

Av. Esperança, s/n, Campus Samambaia, CEP 74690-900, Goiânia - GO, Brasil

Endereço eletrônico: btfcurado@gmail.com

Recebido em: 16/05/2016

Reformulado em: 04/11/2016

Aceito em: 04/11/2016

\section{Notas}

* Mestre em Psicologia pelo Programa de Pós-graduação em Psicologia da Universidade Federal de Goiás (UFG-GO), Goiânia-GO.

** Mestre em Psicologia Clínica e Cultura pela Universidade de Brasília (UnB), Brasília-DF. 